\title{
HUBUNGAN TINGKAT PENGETAHUAN DENGAN KEPATUHAN DIET HIPERTENSI DI PUSKESMAS ASTAMBUL
}

\author{
Martini, Nur Sukmawaty ${ }^{1}$; Maria, Insana ${ }^{2}$; Mawaddah, Norlatifah Sarifatul ${ }^{3}$ \\ ${ }^{1,2}$ Dosen Sekolah Tinggi Ilmu Kesehatan Intan Martapura \\ ${ }^{3}$ Mahasiswa Sekolah Tinggi Ilmu Kesehatan Intan Martapura \\ Email: maria.insana82@gmail.com
}

\begin{abstract}
INTISARI
Latar Belakang: Hipertensi atau yang lebih dikenal dengan sebutan penyakit darah tinggi adalah suatu keadaan dimana tekanan darah seseorang berada di atas batas normal atau optimal yaitu 120 $\mathrm{mmHg}$ untuk sistolik dan $80 \mathrm{mmHg}$ untuk diastolik. Tingkat pengetahuan seseorang disinyalir memiliki hubungan yang cukup kuat untuk menginisiasi aksi kepatuhan seseorang untuk menjalankan diet. Tujuan penelitian ini adalah untuk mengetahui hubungan tingkat pengetahuan dengan kepatuhan diet hipertensi pada penderita hipertensi di Puskesmas Astambul.

Metode: Penelitian ini menggunakan metode deskriptif analitik dengan desain penelitian korelasi dengan teknik purposive sampling, dengan jumlah populasi 5.823 orang dan jumlah sampel sebanyak 98 orang.

Hasil: Penelitian ini menunjukkan hasil uji statistik $0,000 \leq 0,05$ yang berarti $\mathrm{H} 0$ gagal diterima, artinya ada hubungan antara tingkat pengetahuan dengan kepatuhan diet hipertensi di Puskesmas Astambul pada tahun 2019.

Kesimpulan: Penelitian ini menunjukkan ada hubungan antara tingkat pengetahuan dengan kepatuhan diet hipertensi pada pasien dengan masalah hipertensi di Puskesmas Astambul, Kalimantan Selatan. Penelitian ini menunjukkan bahwa petugas kesehatan perlu memberikan intervensi seperti memberikan saran kepada keluarga yang mempunyai anggota keluarga yang menderita penyakit hipertensi untuk memeriksa anggota keluarganya bila sudah ada tanda dan gejala hipertensi.
\end{abstract}

Kata Kunci: Pengetahuan, Kepatuhan, Diet Hipertensi, Hipertensi 


\section{PENDAHULUAN}

Hipertensi dikategorikan sebagai the silent disease dalam jangka waktu lama dan terus menerus memicu stoke, serangan jantung, gagal jantung, dan merupakan penyebab utama gagal ginjal kronik. Penyakit Hipertensi tidak dapat disembuhkan tetapi penyakit yang dapat dikontrol melalui proses pelaksanaan penyakit Hipertensi yang tepat salah satunya dengan peningkatan pengetahuan tentang hipertensi dan kepatuhan terhadap diet. (Joyce M Balck \& Jane Hokanson, 2014).

Prevalensi hipertensi di Indonesia sebanyak 26,5\% dengan Bangka Belitung menjadi provinsi yang memiliki persentase kejadian hipertensi terbanyak 30,9\%, diikuti Kalimantan Selatan 30,8\% (Riskesdas, 2013). Penyakit hipertensi merupakan penyakit nomor 5 terbanyak di Kabupaten Banjar dengan jumlah kasus sebanyak 87.953 kasus. Hasil studi pendahuluan di Puskesmas Astambul pada bulan Oktober sampai November 2018 yang diambiil dari 8 responden mendapatkan hasil 5 di antaranya tidak patuh menjalankan diet hipertensi dan 3 orang patuh menjalani diet pada penyakit Hipertensi.

Penderita Penyakit Hipertensi
harus memiliki pengetahuan dan kepatuhan diet tentang Hipertensi, pengetahuan merupakan kemampuan untuk membentuk model mental yang menggambarkan obyek dengan tepat dan merepresentasikannya dalam aksi yang dilakukan terhadap suatu obyek, sedangkan kepatuhan adalah sejauh mana perilaku pasien sesuai dengan ketentuan yang diberikan oleh profesional (Notoatmodjo, 2010).

Hipertensi merupakan penyakit multifaktoral yang disebabkan oleh berbagai faktor yaitu faktor individu seperti umur, jenis kelamin, faktor genetik. Adapun faktor lingkungan seperti stress juga memiliki pengaruh terhadap hipertensi (Insana Maria, 2018). Hipertensi dapat dicegah dan dikontrol dengan cara mengatur diet yang tepat (seperti mengurangi konsumsi makanan yang mengandung garam, lemak dan kolesterol serta diet tinggi serat), olahraga yang teratur, menghindari konsumsi alkohol, menghindari stress dan mengonsumsi obat antihipertensi sesuai anjuran dokter serta melakukan check-up atau pemeriksaan tekanan darah secara berkala. (Dewi Yulyan Nur Yusuf, 2013).

Uraian pada penyakit hipertensi terkait sebagai penyakit silent disease, mutifactor disease, serta pentingnya pengetahuan dan kepatuhan diet penderita penyakit Hipertensi maka peneliti tertarik meneliti hubungan tingkat pengetahuan dengan kepatuhan diet Hipertensi di Puskesmas Astambul Tahun 2019.

\section{METODE}

Metode penelitian yang digunakan untuk penelitian ini adalah kualitatifkorelasional. Penelitian ini dilaksanakan di Puskesmas Astambul dengan populasi yang diteliti dalam penelitian ini adalah penderita Hipertensi sebanyak 5823 orang dan jumlah sampel 98 responden. Teknik sampling yang digunakan dalam penelitian ini ialah teknik non probability sampling jenis consecutive sampling, yaitu dengan memilih dan memasukkan semua subyek yang memenuhi kriteria penelitian sampai kurun waktu tertentu, sehingga jumlah subyek penelitian yang diperlukan dipenuhi (Morris, E. 2013). Pemilihan tepat responden didukung dengan kriteria inklusi yaitu responden yang di rawat jalan pada Puskesmas Astambul. Metode pengambilan data terdiri dari data primer yang didapat langsung dari responden dengan menggunakan instrumen berupa kuesioner yang didapat dari studi literatur pada teori pengetahuan dan kepatuhan diet penderita hipertensi sedangkan data sekunder merupakan dukungan data dari 
Puskesmas Astambul. Uji statistik yang dilakukan dengan menggunakan ChiSquare.

\section{HASIL}

\section{Karakteristik Responden}

a. Karakteristik responden berdasarkan umur

Tabel 1.1 Distribusi Frekuensi

Berdasarkan Umur.

\begin{tabular}{cccc}
\hline No. & Umur & Frekuensi & $\begin{array}{c}\text { Persentase } \\
\text { \% }\end{array}$ \\
\hline 1. & $21-30$ & 4 & $4.1 \%$ \\
& Tahun & & \\
\hline 2. & $\begin{array}{c}31-40 \\
\text { Tahun }\end{array}$ & 22 & $22.4 \%$ \\
\hline 3. & $\begin{array}{c}\text { > } 40 \\
\text { Tahun }\end{array}$ & 72 & $73.5 \%$ \\
\hline & & \\
\hline
\end{tabular}

Sumber : Data Primer yang telah diolah (2019)

Berdasarkan tabel 1.1 menunjukkan karakteristik responden berdasarkan umur yang tertinggi adalah responden berumur $>40$ tahun yaitu sebanyak 72 orang dari 98 responden dengan persentase $(73,5 \%)$.

b. Karakteristik Berdasarkan Pendidikan

Tabel 1.2 Distribusi Frekuensi Berdasarkan Pendidikan

\begin{tabular}{clcc}
\hline No. & $\begin{array}{c}\text { Latar Belakang } \\
\text { Pendidikan }\end{array}$ & Frekuensi & \% \\
\hline 1. & Tidak sekolah & 0 & 0 \\
\hline 2. & SD (sekolah dasar) & 20 & 20.4 \\
\hline 3. & $\begin{array}{l}\text { SMP (sekolah } \\
\text { menengah pertama) }\end{array}$ & 35 & $35,7 \%$ \\
\hline 4. & $\begin{array}{l}\text { SMA (sekolah } \\
\text { menengah atas) }\end{array}$ & 43 & $43,9 \%$ \\
\hline 5. & Perguruan tinggi & 0 & $0 \%$ \\
\hline \multicolumn{4}{c}{ Jumlah } \\
\hline Berdasarkan tabel 1.2 menunjukkan \\
bahwa \\
latar mayoritas responden memiliki \\
$\quad$ belakang pendidikan SMA
\end{tabular}

(Sekolah menengah atas) sebanyak 43 responden $(43.9 \%)$.

c. Pengetahuan Pasien Hipertensi

Tabel 1.3 Distribusi Kategori Tingkat Pengetahuan Pasien Hipertensi.

No. Kategori Jumlah Pesentase

(\%)

\begin{tabular}{cccc}
\hline 1. & Baik & 74 & $75.5 \%$ \\
\hline 2. & Cukup & 24 & $24.5 \%$ \\
\hline 3. & Kurang & 0 & $0 \%$ \\
\hline & Jumlah & $\mathbf{9 8}$ & $\mathbf{1 0 0 \%}$
\end{tabular}

Sumber : Data Primer yang telah diolah (2019)

Berdasarkan tabel 1.3 diatas menunjukkan bahwa mayoritas tingkat pengetahuan responden adalah kategori baik yaitu sebanyak 74 responden (75.5\%).

d. Karakteristik Berdasarkan Kepatuhan

Tabel 1.4 Distribusi Frekuensi

Responden berdasarkan Kepatuhan No. Kategori Frekuensi Persentase

\begin{tabular}{cccc} 
& & & $(\%)$ \\
\hline 1. & Patuh & 98 & $100 \%$ \\
\hline $\begin{array}{l}\text { Tidak } \\
\text { patuh }\end{array}$ & 0 & $0 \%$ \\
\hline Jumlah & $\mathbf{9 8}$ & $\mathbf{1 0 0 \%}$
\end{tabular}

Sumber : Data Primer yang telah diolah (2019)

Berdasarkan tabel 1.4 diatas menunjukkan bahwa mayoritas kepatuhan responden adalah kategori patuh yaitu sebanyak 98 responden $(100 \%)$.

e. Tabulasi silang tingkat pengetahuan dengan kepatuhan diet hipertensi pada penderita hipertensi. 
Tabel 1.5 Tingkat Pengetahuan Dengan Kepatuhan Diet Hipertensi pada Penderita Hipertensi

\begin{tabular}{|c|c|c|c|c|}
\hline $\begin{array}{c}\text { No } \\
\text {. }\end{array}$ & $\begin{array}{c}\text { Pengetahua } \\
\text { n }\end{array}$ & $\begin{array}{c}\text { Kepatuha } \\
\text { n }\end{array}$ & Total & $\begin{array}{c}\mathbf{P} \\
\text { valu }\end{array}$ \\
\hline • & & Patuh & & e \\
\hline \multirow[t]{3}{*}{1.} & Baik & 74 & 74 & 0,00 \\
\hline & & $75.5 \%$ & 75.5 & 0 \\
\hline & & & $\%$ & \\
\hline \multirow[t]{5}{*}{2.} & Cukup & 24 & 24 & \\
\hline & & $24.5 \%$ & 24.5 & \\
\hline & & & $\%$ & \\
\hline & Total & 98 & 98 & \\
\hline & & $100 \%$ & $100 \%$ & \\
\hline
\end{tabular}

Sumber: Data Primer yang telah diolah (2019)

Berdasarkan tabel 1.5 dapat diketahui bahwa 74 responden memiliki tingkat pengetahuan yang baik, dengan patuh melakukan diet hipertensi, dan 24 responden memiliki tingkat pengetahuan cukup dengan patuh melakukan diet hipertensi.

f. Hasil Uji Chi-Square Antara Tingkat Pengetahuan Dengan Kepatuhan Diet Hipertensi

Tabel 1.6 Hasil Uji Chi-Square Antara Tingkat Pengetahuan Dengan Kepatuhan Diet Hipertensi

\begin{tabular}{ccc}
\hline Variabel & $\mathbf{P}$ & $\mathbf{N}$ \\
\hline Tingkat & 0,000 & 98 \\
Pengetahuan & & \\
dengan & & \\
Kepatuhan & & \\
Diet & & \\
Hipertensi & &
\end{tabular}

Sumber : Data Primer yang telah diolah (2019)
Berdasarkan hasil pengolahan data antara tingkat pengetahuan dengan kepatuhan diet hipertensi menggunakan uji statistik ChiSquare diketahui nilai $\mathrm{p}=0,000(\mathrm{p}$ $=0,000<0,05), \mathrm{H} 0$ gagal diterima yang berarti ada hubungan yang signifikan antara Tingkat Pengetahuan Dengan Kepatuhan Diet Hipertensi Di Puskesmas Astambul Tahun 2019.

\section{PEMBAHASAN}

Partisipan dengan umur yang tertinggi dalam penelitian ini adalah responden berumur $>40$ tahun yaitu $73,5 \%$. Temuan ini di dukung oleh teori yang menyatakan bahwa semakin tua usia seseorang, maka Ia diharapkan untuk menjadi lebih bijakasana dalam mencari, memperoleh dan mengolah informasi yang diberikan kepadanya.

Latar belakang pendidikan mayoritas responden SMA (Sekolah Menengah Atas) sebanyak $43.9 \%$ diketahui pengetahuan responden yang baik bisa dipengaruhi oleh banyak faktor, misalnya pendidikan, pengalaman, serta sarana informasi (Notoatmojo, 2010). Pengetahuan tidak hanya didapat secara formal melainkan juga melalui pengalaman, semakin banyak informasi yang dijumpai dan semakin banyak hal yang dikerjakan sehingga menambah pengetahuannya terutama terpaparnya informasi dari pendidikan informal dari petugas kesehatan mengenai penyakitnya. Kenyataan ini menjadi peluang besar bagi perawat untuk memberikan informasi seluarnya bagi penderita Hipertensi (Insana Maria, 2018). 
Mayoritas tingkat pengetahuan responden adalah kategori baik yaitu sebanyak $75.5 \%$ kemudian kepatuhan responden adalah kategori patuh yaitu sebanyak $100 \%$. Hal ini menyatakan bahwa kepatuhan seseorang dipengaruhi oleh beberapa faktor yaitu pengetahuan. Semakin tinggi pengetahuan, maka seseorang akan patuh dalam menjalankan diet hipertensi, sedangkan semakin rendah pengetahuan, maka seseorang cenderung tidak patuh dalam menjalankan diet hipertensi. Dengan demikian, perilaku yang didasari oleh pengetahuan akan lebih lama daripada perilaku yang tidak didasari oleh pengetahuan (Ellia Ariesti, 2018).

Terdapat hubungan yang signifikan antara Tingkat Pengetahuan dengan Kepatuhan Diet Hipertensi. Hal ini sesuai dengan teori dari Wawan \& Dewi (2011) yang menyatakan bahwa salah satu faktor yang mempengaruhi kepatuhan yaitu pengetahuan. Pengetahuan merupakan hasil "tahu" dan ini terjadi setelah penginderaan terhadap suatu objek tertentu. Sebagian besar pengetahuan manusia diperoleh melalui mata dan telinga. Pengetahuan merupakan domain penting untuk menentukan tindakan seseorang, karena dari pengalaman dan penelitian membuktikan bahwa perilaku didasari oleh pengetahuan (Ellia Ariesti, 2018).

\section{KESIMPULAN}

Berdasarkan hasil penelitian dan pembahasan yang telah dilakukan peneliti dapat diambil kesimpulan bahwa mayoritas responden yang menggunakan fasilitas Puskesmas Astambul memiliki tingkat pengetahuan baik $75.5 \%$ sedangkan seluruh responden yang menggunakan fasilitas Puskesmas
Astambul memiliki kepatuhan yang patuh terhadap diet hipertesi 100\%. Selanjutnya, terdapat hubungan yang signifikan antara tingkat pengetahuan dengan kepatuhan diet Hipertensi pada masyarakat di Puskesmas Astambul tahun 2019, ditunjukkan dengan nilai $\mathrm{p}=0,000(\mathrm{p}=$ $0,000<0,05)$.

Berdasarkan analisis hasil penelitian dan pembahasan tentang Hubungan Tingkat Pengetahuan Dengan Kepatuhan Diet Hipertensi di Puskesmas Astambul Tahun 2019, peneliti ingin menyampaikan saran sebagai berikut :

1. Bagi tempat penelitian: Diharapkan seluruh petugas kesehatan yang ada di Puskesmas Astambul lebih aktif lagi untuk memberikan penyuluhan kesehatan mengenai Tingkat Pengetahuan dengan Kepatuhan Diet Hipertensi. Peneliti juga mengharapkan agar seluruh petugas kesehatan juga memberikan saran kepada keluarga yang mempunyai anggota keluarga yang menderita penyakit hipertensi memberikan dukungan untuk memeriksa anggota keluarganya bila sudah ada tanda dan gejala hipertensi, serta diharapkan saat selesai pemeriksaan tekanan darah petugas kesehatan memberikan lefleat tentang hipertensi.

2. Bagi responden

Diharapkan dengan penelitian ini, dapat membantu responden meningkatkan pengetahuan tentang hipertensi sehingga responden tersebut dapat melakukan diet hipertensi dengan baik.

\section{ACKNOWLEDGMENT}


Terimakasih Kepada Kepala Puskesmas Astambul telah memberikan kesempatan untuk melaksanakan penelitian dan kepada Mahasiswa Stikes Intan Martapura dalam membantu proses penelitian.

\section{DAFTAR PUSTAKA}

Dewi Yulyan Nur Yusuf. 2013. Gambaran Perilaku Penderita Hipertenisi Dalam Upaya

Mencegah Kekambuhan Hipertensi Di Wilayah Kerja Puskesmas Dolalowo Kota

Gorontalo.

Ellia Ariesti. 2018. Hubungan Self Efficacy Dengan Tingkat Kepatuhan Pengobatan Hipertensi Di Puskesmas Bareng Kota Malang.

Insana Maria (2018). Gangguan Rasa Nyaman Pada Pasien Hipertensi. Jurnal Kesehatan Suaka Insan 3 (2) 1-9

Joyce M Balck \& Jane Hokanson. 2014. Keperawatan Medikal Bedah Manajemen Klinis

untuk hasil yang di harapkan Edisi 8 Buku ke 3. Elseiver. Jakarta

Morris, E. 2013. Sampling for Small Population. Sampling for Small Population Available from : http://uregina.ca/ morrisev/sociology/sa mpling\%20from\%20small\%20population s.htm ( Accessed 7 Februari 2014).

Notoatmojo, (2010). Metodologi Penelitian Kesehatan. Jakarta : PT Rineka Cipta.

Sunarti. 2015. Upaya Penderita Hipertensi Untuk Mempertahankan Pola Hidup Sehat
(Hypertension Patients Effort to Maintain Healthy Lifestyles).

Widho Fahkurnia. 2017. Gambaran Self Care Pada Penderita Hipertensi Di Wilayah Kerja Puskesmas Gatak Kabupaten Sukoharjo. 